\section{EDUCAÇÃO}

V.10 • N.2 • Número Temático - 2020

ISSN Digital: 2316-3828

ISSN Impresso: 2316-333X

DOI: 10.17564/2316-3828.2020v10n2p80-94
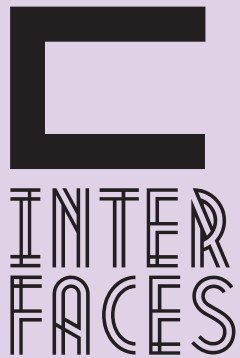

CIENTÍFICAS

\title{
RELAÇ̃̃ES SOCIOTÉCNICAS DO MOVIMENTO ESCOLA SEM PARTIDO A PARTIR DE UMA ANÁLISE PÓS-QUALITATIVA ${ }^{1}$
}

SOCIOTECHNICAL RELATIONSHIPS OF THE SCHOOL WITHOUT A PARTY MOVEMENT FROM A POST-QUALITATIVE ANALYSIS

\section{RELACIONES SOCIOTECNICAS DEL MOVIMIENTOESCUELA SIN PARTIDO UN ANÁLLISIS POSCUALITATIVO}

Patrícia Silva Nelson De Luca Pretto ${ }^{3}$

Danillo Mota Lima ${ }^{4}$

\section{RESUMO}

Este artigo traça as relações sociotécnicas no Movimento Escola sem Partido a partir de uma visão pós-humana e da análise pós-qualitativa; utiliza como arcabouço teórico a Actor-Network Theory, que começa com o foco na materialidade e é alimentada pela observação que os humanos não são/estão totalmente no controle das práticas, mas apoiada pela suposição de que os objetos/coisas também participam e contribuem para a formação delas. Aplicamos a metodologia pós-qualitativa, mostrando que a produção de fatos científicos não parte apenas dos humanos, mas sim das associações e das mixagens das entidades. Aquele que age e se movimenta, modifica o cenário e deixa rastros, de modo que cabe ao pesquisador descrever as marcas deixadas pelos atores (humanos e não-humanos), delineando as conexões existentes entre eles. Esse conhecimento é determinado, produzido e visível por meio dessas conexões.

\section{PALAVRAS-CHAVE}

Sociomaterialidade. Teoria Ator-Rede. Movimento Escola sem Partido. Pesquisa Pós-Qualitativa. 


\section{ABSTRACT}

This article traces the sociotechnical relations in the School Without a Party Movement from a post-human perspective and from post-qualitative analysis, using Actor-Network Theory as a theoretical framework, which begins with a focus on materiality and is fed by observation that humans are not totally in control of practices, but supported by the assumption that objects/things also participate and contribute to their formation. We apply the post-qualitative methodology, showing that the production of scientific facts does not come only from humans, but from associations and mixtures of entities. The one who acts and moves, changes the scenario and leaves traces, so that it is up to the researcher to describe the marks left by the actors (human and nonhuman), outlining the existing connections between them. This knowledge is determined, produced and visible through these connections.

\section{KEYWORDS}

Sociomateriality; Actor-Network Theory; School Without Party Movement; Post-Qualitative Research.

\section{RESUMEN}

Este artículo traza las relaciones sociotécnicas en el Movimiento de la Escuela Sin Partido desde una perspectiva poshumana y desde un análisis poscualitativo, utilizando la Teoría del Actor-Red como marco teórico, que comienza con un enfoque en la materialidad y se alimenta de observación de que los humanos no están totalmente en control de las prácticas, pero respaldados por la suposición de que los objetos/cosas también participan y contribuyen a su formación. Aplicamos la metodología poscualitativa, mostrando que la producción de hechos científicos no proviene solo de humanos, sino de asociaciones y mezclas de entidades. El que actúa y se mueve, cambia el escenario y deja huellas, de modo que corresponde al investigador describir las marcas dejadas por los actores (humanos y no humanos), describiendo las conexiones existentes entre ellos. Este conocimiento está determinado, producido y visible a través de estas conexiones.

\section{PALABRAS CLAVE}

Sociomaterialidad; Teoría del Actor-Red; Movimiento de la Escola Sem Partido; Investigación poscualitativa. 


\section{INTRODUÇ̃̃̃o}

Estamos cercados por um mundo composto por pessoas, estrelas, animais, elétrons, usinas nucleares, mercado, política, algoritmos etc., ou seja, vivemos rodeados por todo e qualquer coletivo humano e não-humano ${ }^{5}$, existimos em um mundo híbrido, que são espaços abertos, em que grupos podem se reunir para discutir soluções técnicas, envolvendo a coletividade, e que tem, por natureza, a heterogeneidade dos atores envolvidos.

Posto isto, este artigo traça as relações sociotécnicas no Movimento Escola sem Partido (MEsP) a partir de uma visão pós-humana e da análise pós-qualitativa, começa com o foco na materialidade e é alimentada pela observação que os seres humanos não são/estão totalmente no controle das práticas, mas apoiados pela suposição de que os objetos/coisas ${ }^{6}$ também participam e contribuem para a formação delas. Em suma, nós precisamos mostrar como as coisas que as pessoas fazem, fazem as pessoas a fazer coisas. Utilizamos como aporte teórico a Actor-Network Theory (ANT), uma abordagem baseada na materialidade relacional.

A controvérsia MEsP, laboratório da pesquisa, ultrapassou as fronteiras geográficas e se estabeleceu no mundo digital, onde os atores construíram relacionamentos e personas em redes. Dessa forma, nos concentramos nas rotinas dos participantes (humanos e não-humanos) que ocorriam no âmbito virtual nos anos de 2016 à 2019, a partir das matérias jornalísticas do portal de notícia Globo, sites governamentais (Senado e Câmara Federal), instituições (Movimento Escola sem Partido), discussões em redes sociais (Facebook), mostrando a construção do social.

\section{SOCIAL+MATERIAL = SOCIOMATERIALIDADE}

O conceito de social tem muitos significados diferentes, contudo a palavra latina socius, que significa associar e tem sentindo de incluir qualquer coisa e tudo o que pode ser associado. Assim, social (conexões, interações) podem incluir plantas, animais, artefatos, humanos, objetos/coisas etc.

0 social é aquilo que se manifesta a partir das associações e como essas associações se estabilizam, produzindo o social (LATOUR, 2012). O social e o material estão profundamente conectados e não existe social que não seja material, e nenhum material que não seja também social (BUHL; ANDERSEN; KEROSUO, 2019). Somos associados por redes sociotécnicas.

Quando se fala em redes sociotécnicas faz-se referência a um aglomerado de relações humanas com os objetos/coisas, também envolvem discursos, imaginários, eventos, entre outros, e a interação destas partes distintas. Cada humano e/ou não-humano está associado a outros partícipes numa rede sociotécnica.

Logo, o social é tudo que integra sujeitos/objetos/coisas e sem essa integração não existiria sociedade, uma vez que as interações são realizadas por e por meio de objetos/coisas.

Vejamos alguns exemplos: no catolicismo imagens sacras condicionam sobremaneira alguns 
comportamentos dos fiéis; o que seria do musicista sem seu instrumento? E o cardiopata sem o marcapasso cardíaco? Como pensar a mobilidade urbana sem os semáforos, lombadas?

Ser social é associar-se e estudar o social é estudar associação em todas as suas formas materiais (DUIJN, 2009). Para a ANT, o domínio do social inclui humanos, micróbios, vieiras, navios, chaleiras, sabão, macacos, colisões de velocidade, precedentes legais, objetos/coisas.

Assim sendo, o primeiro passo ao se estudar a sociomaterialidade tem a ver com desvincular-se da nossa herança humanista, pois apenas esquecendo aspiração humana é possível começar a lidar seriamente com a materialidade (SØRENSEN, 2009).

O termo sociomaterialidade enquadra e enuncia a impossibilidade em se pensar o social apartado do material e vice-versa. Falar sobre a sociomaterialidade é reconhecer e sempre lembrar que a materialidade atua como um elemento constitutivo do mundo social.

Enquanto a materialidade pode ser uma propriedade de uma tecnologia, a sociomaterialidade representa a promulgação de um conjunto particular de atividades que fundem a materialidade com instituições, normas, discursos etc. (LEONARDI, 2012).

A palavra materialidade não se refere apenas aos materiais dos quais uma tecnologia é criada e não é sinônimo de fisicalidade. Toda materialidade que é criada é social por meio de processos sociais e é interpretada e usada em contextos sociais, e toda ação social é possivel por causa de alguma materialidade (MONTERROZA, 2017; LEONARDI, 2012). Desse modo, a materialidade presente no conjunto de objetos que compõem uma cultura material (edifícios, ferramentas, armas, textos escritos, vestidos etc.), permite às sociedades manter sua durabilidade.

\section{PRINCÍPIOS DA ACTOR-NETWORK THEORY [ANT]}

ANT recomenda narrar às associações e registrar as ações dos grupos inseridos num processo de coletividade, isto é, o movimento realizado não é uma qualidade exclusivamente de humanos, mas de uma associação de atores não-humanos também. Nessa perspectiva teórica, humanos e não-humanos agem e podem transformar as situações que estão envolvidos.

Como primeiro princípio temos "seguir as coisas através das redes em que elasse transportam" (LATOUR, 2004, p. 397), daí a palavra ant, que em inglês significa formiga, ser a tradução perfeita para o detalhismo e a qualidade de rastreador de trilhas (LATOUR, 2012), de quem se identifica com essa teoria, originária da antropologia e a serviço da "sociologia das associações, das reassociações e das reconfigurações entre agentes humanos e não-humanos”, seguindo os caminhos traçados por eles, assim como a formiga faz sua caminhada (BENNERTZ, 2011, p. 949).

O segundo princípio diz respeito a igualdade de tratamento entre as entidades, observando-as ao mesmo tempo, não se presumindo diferenciação de nível entre os atores na análise dos fenômenos sociais. Essa intervenção de equivalência é chamada de simetria generalizada.

A proposta de uma simetria generalizada refere-se principalmente a igualdade semiótica de pessoas e coisas, ou melhor, o nivelamento semiótico das diferenças entre as pessoas e as coisas 
(SCHUBERT, 2019). Latour (2012), nos mostra essa questão claramente na reformulação do conceito de ator como actante. De acordo com sua perspectiva relacional, nem o material, nem o lado social possuem posições dominantes.

O ator/actante é tudo aquilo - humano e/ou não-humano - que provoca uma ação, tudo que age, que proporciona um deslocamento e consequentemente uma mudança. Segundo Laet e Mol (2000), o termo ator é construído sobre a tradição da semiótica francesa, na qual “ator” é um termo técnico para todas as entidades ativas, ao invés de um título de honra que pode ser usado apenas para humanos. 0 uso do termo ator é refutado, pois tende a se limitar a atores humanos, assim é sugerido o termo actante.

E como último princípio, a não-purificação, que nega as divisões, que difundem as separações entre humanos e não-humanos, que expandem o binarismo entre natureza e sociedade, ciência e senso comum, entre outras coisas mais. Portanto, ANT nos convida a lançar na 'fogueira dos dualismos', as distinções convencionais: natureza/sociedade, humanos/não-humanos, estrutura/agência, distinguindo-a da maioria de abordagens filosóficas que muitas vezes tratam essas categorias como um ponto de partida relativamente não problemática (KANGER, 2017). Sujeitos e objetos/coisas se enredam, se apoiam um no outro, sem a purificação do sujeito e sem o conformismo do objeto/coisa.

Para a ANT não há elementos puros, por exemplo, pessoas/objetos/coisas, essa distinção só pode ser feita a partir de um trabalho de purificação que cria dois planos ontológicos distintos, só pode se realizar apoiada numa prática de desmembramento e hierarquização, que se compromete em entender situações, campos e espaços de formas separadas. Lembremos que somos quase-sujeitos e quase-objetos e quanto mais temos um, mais temos o outro (LATOUR, 1994).

Como as condições para utilizar a ANT são mais indicadas na presença de conflitos e embates, os defensores dessa abordagem sugerem que iniciemos com a identificação de uma controvérsia, ou seja, a partir de opiniões distintas acerca de uma ação sobre a qual muitas pessoas divergem. Para tornar as discussões mais concretas, optamos por analisar o MEsP e compreender as relações tecno-políticas e sociotécnicas, utilizando as lentes do ator-rede.

\section{MOVIMENTO ESCOLA SEM PARTIDO [MESP]}

O MEsP foi criado pelo advogado Miguel Nagib. Em 2014, o deputado estadual do Rio de Janeiro, Flávio Bolsonaro (PSC-RJ) pediu ao Miguel Nagib que escrevesse um projeto de lei (PL) com esse teor. Em seguida, apareceu o segundo projeto, também no Rio de Janeiro, apresentado pelo vereador Carlos Bolsonaro (PSC-RJ). O MEsP ganhou notoriedade em 2015 e começaram a ser apresentados e debatidos em inúmeras câmaras municipais e assembleias legislativas e no Congresso Nacional.

A polêmica em torno dos projetos de lei envolve diversos fatores de ordem jurídica, política, social e educacional. Apoiadores e críticos aos projetos debatem se ele fere ou não a Constituição, se é possível ensinar com neutralidade e até que ponto a educação familiar deve ter influência no ensino escolar. Contrários ao texto argumentam que o projeto não permitirá o pensamento crítico em sala de aula. Defensores alegam que a proposta tem como objetivo evitar a "doutrinação" nas escolas. 
De forma geral, 0 objetivo da MEsP é pregar uma educação apartidária, sem doutrinação e livre de ideologias, buscando estabelecer os deveres e direitos dos professores, com a fixação de um cartaz em sala de aula, entre outras determinações, a partir dos Projetos de Lei 867/2015, 193/2016 e 246/2019; como forma de auxiliar pais e alunos, que se sintam doutrinados pelos professores, assim, delimitando os limites de atuação desses profissionais em suas práticas pedagógicas.

\section{PESQUISA PÓS-QUALITATIVA}

Na perspectiva da ANT, a produção de fatos científicos não parte apenas dos humanos, mas sim das associações e, consequentemente, das mixagens das entidades. Portanto, uma das decorrências metodológicas do olhar apresentado por Latour (2012), é que a pesquisa não se debruce apenas sobre os humanos, mas igualmente na agência de todos os elementos.

As tendências sociomateriais na metodologia de pesquisa oferecem oportunidades de reunir diferentes aspectos. Ao descentrar os humanos como os únicos possíveis conhecedores e produtores de conhecimento, uma riqueza de possibilidades de pesquisas surgem (ULMER, 2017), oferecendo outra reformulação em alinhamento com um novo conjunto de filosofias sobre o social (GREENE, 2013).

Enquanto pensarmos na natureza do humano como ser supremo, a materialidade não importará, mas a partir do momento que percebemos humanos-não-humanos fundidos, emaranhados, associados, fazendo as coisas acontecerem, por que não tentar algo distinto? Pois bem, as diferentes formas de pensar e fazer pesquisas surgem como uma alternativa aos estudos pós-humanistas, sob um termo abrangente chamado "pesquisa pós-qualitativa” (ST. PIERRE, 2018a; 2018b; LE GRANGE, 2018; ULMER, 2017; GERRARD; RUDOLPH; SRIPRAKASH, 2017).

A investigação pós-qualitativa emergiu nos últimos anos como um movimento metodológico situado dentro da ampla "virada sociomaterialista" (GERRARD; RUDOLPH; SRIPRAKASH, 2017). A pesquisa pós-qualitativa é, portanto, pós-antropocêntrica (LE GRANGE, 2018).

O envolvimento com a pesquisa pós-qualitativa implica em maneiras profundamente diferentes de pensar sobre o design da pesquisa. A pesquisa pós-qualitativa adota medidas mais abertas, flexíveis e descritivas. O importante é chegar a um entendimento integrado da composição relacional de uma prática específica sob investigação e dos efeitos que essas composições geram. Assim, todas as forças que atuaram sobre e por meio da pesquisa, por exemplo: humanos e não-humanos, se associaram para produzir um conjunto de investigação pós-qualitativa, tornando-se um emaranhamento, uma assembleia de coisas (MAZZEI, 2013).

Logo, o ponto de entrada na análise pós-qualitativa é considerá-la como uma assembleia de coisas, visto que, a multiplicidade no processo a ser pesquisado, tais como: humanos, objetos/ coisas, cenários e espaços físicos, literatura científica e estudos anteriores, pressupostos teóricos, dados produzidos por métodos e técnicas etc., procura o efeito que unem essa assembleia (FOX; ALLDRED, 2017).

Taylor (2017), identifica algumas características-chaves da pesquisa pós-qualitativa e como tais características compartilham uma orientação pós-humanista, que reformulam questões ontológicas, 
epistemológicas e metodologicas, podem ser usadas no campo educacional, sejam elas:

1. 0 descentramento humano a fim de reconhecer a agência de não-humanos também;

2. A passagem de uma consciência cognitiva para o materialismo relacional;

3. A reformulação epistemológica que rompe com o binarismo do sujeito cartesiano e consequentemente a superação da dicotomia sujeito/objeto.

A pesquisa pós-qualitativa não possui um consenso conceitual, pois está estruturada em vários pressupostos teóricos (as redes rizomáticas o realismo agencial e o poder das coisas). É interessante iniciar a pesquisa pós-qualitativa a partir de uma análise pós-estruturalista (ST. PIERRE, 2018a; 2018b) descritas a partir das características-chaves.

Assim, provocada pelo reposicionamento da pesquisa intitulada pós-qualitativa, e conforme Geiger e Ribes (20110, resolvemos trabalhar a etnografia à sombra da perspectiva das redes sociotécnicas.

\section{ETNOGRAFIA DAS REDES SOCIOTÉCNICAS [ERS]}

Ao falar de etnografia das redes sociotécnicas (ERS), estamos utilizando os preceitos e premissas da etnografia "tradicional", contudo, com distinção em sua execução, uma vez que não iremos nos concentrar apenas nos humanos, e sim, em toda rede sociotécnica. A ERS viabiliza analisar o fenômeno pelo olhar dos participantes da rede (humano e não-humano), introduzindo todos os atores.

A ERS é uma alternativa metodológica que propõe o mapeamento como uma maneira possível de revelar articulações do fenômeno. É uma maneira de reestudar do que somos feitos, o objetivo é compreender a composição relacional de uma prática específica sob investigação e dos efeitos que esses arranjos e vínculos geram. Ela é uma técnica flexível e poderosa, principalmente quando a pergunta da pesquisa envolve a natureza distribuída da ação, porque ela é capaz de capturar muitos fenômenos, que de outra forma, seria difícil de estudar.

Abordar um fenômeno por meio da ERS é mais como usar um microscópio do que uma lente de aumento (LONGO; ZACKA, 2019), encontramos não apenas uma versão ampliada do que vimos de longe, mas novas dimensões da realidade. Dessa forma, a ERS pode configurar uma nova cultura metodológica, por sua natureza diversificada, flexível e heterogênea, além da plasticidade entendida em seus diferentes contextos (PÉREZ MARTÍNEZ; ALCARÁ; MONTEIRO, 2019).

É pertinente afirmar que, embora "poucos trabalhos tratam diretamente do método etnográfico como metodologia de análise" (MONTEIRO, 2012, p. 140), e menos ainda, sobre a ERS, essa ferramenta possibilita deixar o objeto falar, a partir de um olhar minucioso do pesquisador, e de todos os dados por ele produzidos, a fim de se chegar às análises e discussões mais conclusiva dos fatos (VIEIRA, 2016). Portanto, a ERS são mais que ferramentas analíticas, porque elas também são metáforas poderosas de nossa vida coletiva, com toda a sua complexidade e muitas dependências.

\section{ANÁLISES E DISCUSSÃO}


Um novo movimento político foi criado com a controvérsia Escola sem Partido, o "palco de disputas não está só circunscrito à dimensão intelectual, mas também esferas políticas” na construção das "verdades" (LIMA; ORTERMANN; CAVALCANTI, 2018, p. 381). A cada momento de embates (que foram muitos), precisamos reorganizar e reestruturar o entendimento do que estava sendo agregado.

Para rastrear o grupo é necessário deixar o grupo falar a partir dos seus porta-vozes (FIGURA 1), esses grupos não são coisas amordaçadas e se manifestam apoiados pelas controvérsias. Desse modo, para cada grupo definido, temos um antigrupo.

Figura 1 - (Anti)grupos: Porta-vozes da Controvérsia Escola sem Partido Legenda: Humanos e Não-Humanos

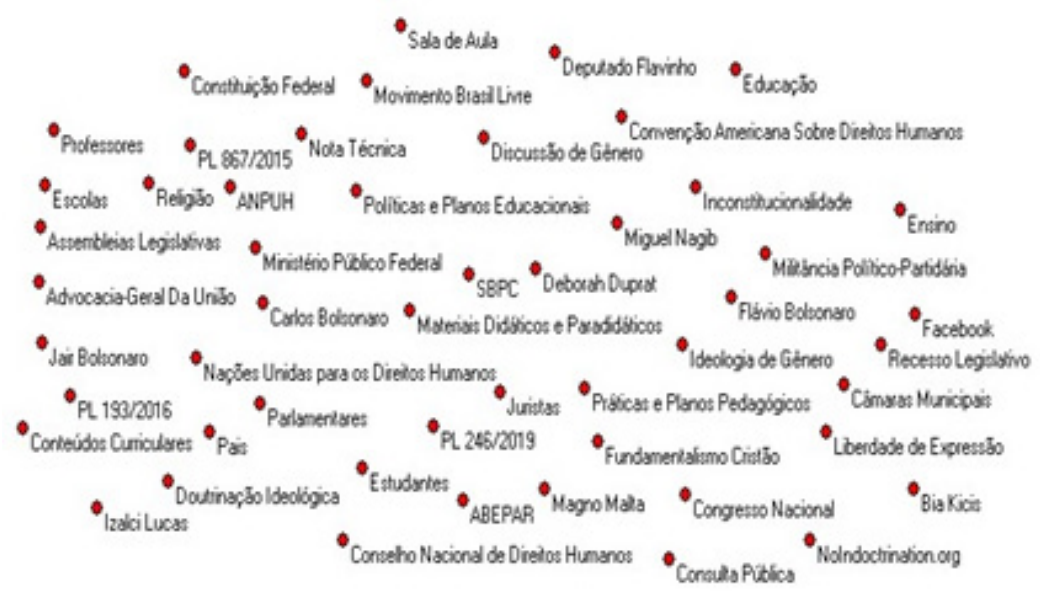

Fonte: Elaborado pelos Autores (2019).

Para expor os porta-vozes da controvérsia MEsP da Figura 1, listamos os humanos e não-humanos presentes no MEsP a partir das redes de informação já mencionadas: portal de notícia Globo, sites governamentais (Senado e Câmara Federal), instituições (Movimento Escola sem Partido), discussões em redes sociais (Facebook). A escolha dessas redes de informação, se deu pela tensão e mobilização dos grupos sociais envolvidos na controvérsia.

As entidades (humanas e não-humanas) por si só não dizem nada, ainda não é uma relação de causa e efeito, contudo elas podem produzir um evento, quando associadas (SEGATA, 2014). Encontramos todo e qualquer grupo que se associa a controvérsia MEsP, além dos estudantes, pais, professores, políticos, ou melhor, humanos; existe também os não-humanos, tais como: os PL, o cartaz, recesso legislativo, a religião, a Constituição Federal, partidos políticos, ou seja, os discursos, imagens, normas, e outras coisas, visíveis ou não visíveis ainda.

Já não temos como identificar os “ingredientes” que entram na composição da controvérsia, tão pouco quem são todos os atores, mas “já é tempo de olhar com mais cuidado o tipo de agregados 
reunidos e os modos como eles se conectam uns aos outros" (LATOUR, 2012, p. 43). A existência dos elementos sociais (humanos e não-humanos) precisam ser revelados em uma situação, mesmo que esses não estejam fisicamente presentes. A ação não pertence a um local específico, é distribuída, múltipla, deslocada, onde quer que os atores estejam, próximos ou distantes, presente ou ausente na rede sociotécnica (FIGURA 2).

Figura 2 - Rede Sociotécnica da Controvérsia Escola sem Partido.

Legendas: Humanos e Não-Humanos Linhas de Associação Cluster Projeto de Lei

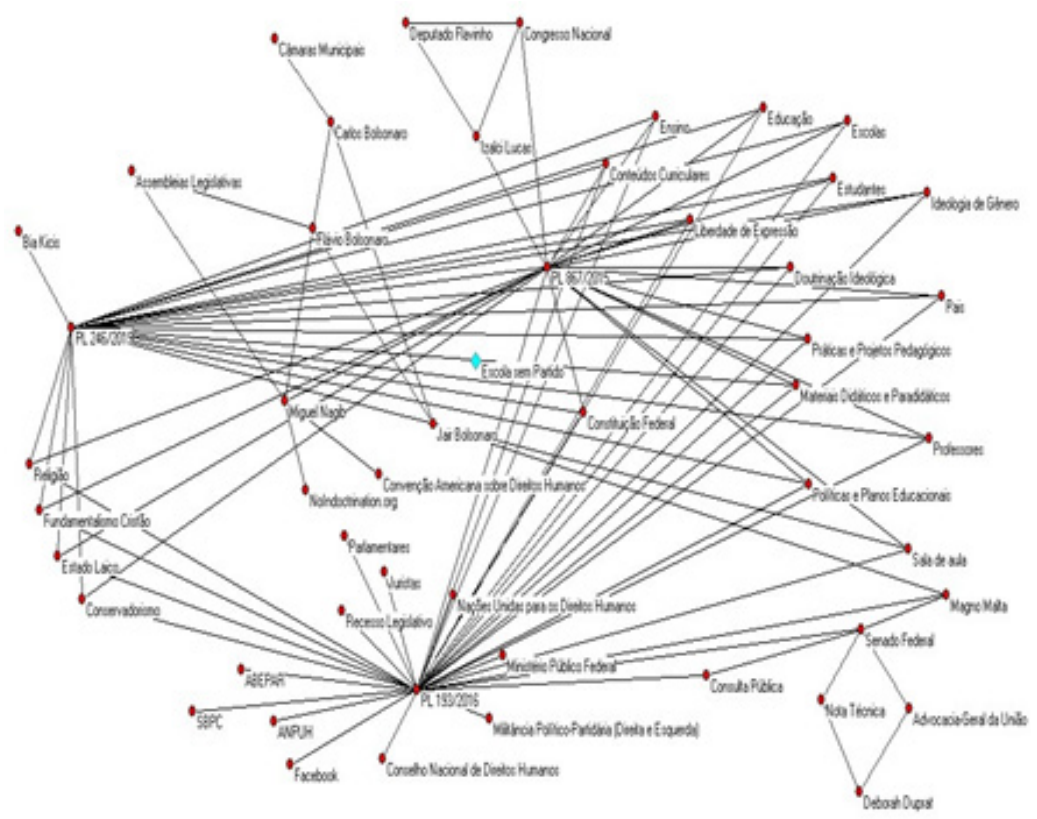

Fonte: Elaborado pelos Autores (2019).

Quando se fala em redes sociotécnicas faz-se referência a um aglomerado de relações humanas com os objetos/coisas, também envolvem discursos, imaginários, eventos etc., e a interação destas partes distintas. A visão principal da ANT sobre o mundo é que todos os objetos, assim como todas as pessoas, conhecimento e localização, são efeitos relacionais. Cada humano e/ ou não-humano está associado a outros partícipes da rede sociotécnica (FIGURA 2), isto é, cada linha de associação se faz entre essas entidades.

Graficamente, humanos e não-humanos são interligados entre si por meio de linhas de associação. No centro da rede, encontra-se a controvérsia MEsP. As linhas utilizadas representam a situação das relações existentes que podem ser: uma relação passada, aquela que já foi consolidada; uma relação atual, onde os atores humanos e não-humanos estão procurando aliados para estabilizar a controvérsia; e relação pretendida, onde existe o processo de negociação, ou seja, uma possibilidade ou não de se rea- 
gregar o social. Em qualquer desses três movimentos, os atores da rede sociotécnica são representados.

A rede de atores humanos e não-humanos envolvidos na controvérsia MEsP apresenta 3 clusters (círculo em cor amarela), que em termos sociotécnicos representam os PL, considerados como atores não-humanos, com elevado número de ligações, pois são motivados pelos mesmos interesses, portanto, associados uns aos outros e, praticamente a toda rede (ROSA; FERREIRA; SILVA, 2020).

Ao observar a rede sociotécnica, nenhuma entidade está isolada e nem apartada das outras, pois essas estão sempre emaranhadas em outras redes, por exemplo, a rede estudantes se encontra associada à rede material didático, e consequentemente a rede professores, que por sua vez, encontra-se relacionada à rede tecnologias e, assim, continuamente. É importante frisar que a rede é híbrida, ou seja, humanos e/ou não-humanos não carecem ser definidos pela sua natureza, melhor dizendo, pelas suas características próprias, mas sim por meio de suas associações, interações e ações (HARMAN, 2009).

Os atores estão enredados. A ação não ocorre paralelamente no espaço/tempo, porque cada ator age de acordo com seu espaço/tempo e potência adquiridos dentro da controvérsia. Outra característica é não termos como visualizar toda a rede, pois essas se desdobram em várias outras redes, explícitas ou não e, consequentemente, influem em várias outras ações.

Em vista disso, "rede é uma expressão para avaliar quanta energia, movimento e especificidade nossos próprios relatos conseguem incluir [...] é uma ferramenta que nos ajuda a descrever algo [...]" (LATOUR, 2012, p. 192). A rede é o próprio social se construindo e se organizando e o social é um movimento provisório de associações.

Os traços deixados na Figura 2 podem ser numerosos e se revelam em formatos diferentes, sejam eles um discurso de um humano, uma imagem, um cartaz, materiais didáticos, o PL, conteúdos curriculares, uma norma, um objeto; visto que a cada ação um rastro é produzido, tais como, quem fala em nome de quem; quem representa quem; qual forma assumir (e isso para justificar a existência do grupo).

A rede é formada num dado instante por uma pluralidade de conexões e nenhum ponto é privilegiado em relação a outro, o que faz com que uma rede tenha múltiplas entradas. Não são os atores ou as redes em si que interessam, mas as conexões e relações que são construídas. “Os vários atores têm diferentes interesses que são negociados e suas estratégias determinam o que é estabilizado e segue adiante" (COSTA; AZEVEDO; PEDRO, 2018, p. 37).

\section{CONSIDERAÇÕES FINAIS}

Aquele que age e se movimenta, modifica o cenário e deixa rastros, de modo que cabe ao pesquisador descrever as marcas deixadas pelos atores (humanos e não-humanos), delineando as conexões existentes entre eles. Esse conhecimento é determinado, produzido e visível por meio dessas conexões e deslocamentos.

No tópico análises e discussões, especificamente na Figura 2, observamos quatro propriedades (MÜLLER, 2015) constituintes da rede sociotécnica MEsP:

1. São relacionais: são arranjos de diferentes entidades ligadas entre si para formar um novo todo; 
2. São produtivas: produzem novas organizações territoriais, novos comportamentos, novas expressões, novos atores e novas realidades;

3. São heterogêneas: não há suposições sobre o que pode ser relacionado (humanos, coisas, objetos, ideias etc.), nem qual é a entidade dominante;

4. São desterritorializadas e reterritorializadas: estabelecem territórios à medida que emergem e se mantêm juntas, mas também constantemente sofrem mutação, se transformam e se separam.

Consiste em múltiplas partes heterogêneas ligadas entre si para formar um todo, não há, portanto, hierarquias pré-determinadas e não há um único princípio organizador por trás das associações, por isso, dizemos que são sociomateriais, sociotécnicas, evitando a divisão entre natureza e cultura (BENNETT, 2010).

Latour (1994b) compreende que as redes sociotécnicas abrangem um espaço abundante de possibilidades que favorecem a produção e a circulação de conhecimento. Para a ANT, as ciências ditas do social, não podem existir se a dúvida do quê e quem contribui na ação não for explorada.

A visão apresentada sobre ERS e suas entidades constitutivas, enquanto objeto de estudo, pode abrir possibilidades, no sentido de orientar um modo de pesquisar, capaz de gerar diferenças, a partir do momento, que estabelece conexões com essas entidades, enquanto exclui outras, como um modo particular de negociar interesses. A maneira como a prática é constituída e as associações relacionais distribuídas, determinam formas específicas, que mudam, dependendo das relações estabelecidas, entre diferentes performances.

As contribuições desta pesquisa estão situadas em torno do desenvolvimento de um vocabulário capaz de articular a relação humano e não-humano, oferecendo, assim, um reforço oportuno para se pesquisar a sociomaterialidade na prática diária. É pensar uma teoria que observa a ação do objeto/ coisa no humano e que esse humano também age no objeto/coisa, imprimindo a mesma função, o mesmo encargo no momento da ação. Isso parece bastante pertinente nos estudos atuais: é uma maneira de estudar o que não podemos "ver" (que parece assustar a supremacia humana), é a necessidade de repensar o meio em que vivemos e a nós mesmos a partir de uma perspectiva reticular e não opositiva.

Para Reddington e Price (2018), a materialidade pode ser usada como uma forma de praxe, para inquietar os modos tradicionais de pensar e testemunhar o emaranhamento que todos os corpos fazem.

Metodologicamente, o objetivo foi contribuir para o diálogo a respeito da etnografia das redes sociotécnicas como forma de conhecer nossa realidade, buscando pensar alternativas metodológicas, como exemplo, a pesquisa pós-qualitativa, que se fundamenta numa visão não-antropocêntrica, desmascarando as maneiras pelas quais estamos enraizados em ideologias humanistas. É isso que o pós-humanismo e a pesquisa pós-qualitativa incentivam: reconceitualizar nosso lugar no mundo à medida que reconceitualizamos a metodologia de pesquisa.

\section{REFERÊNCIAS}

BENNERTZ, R. Constituindo coletivos de humanos e não humanos: a ordenação do mundo. História, Ciências, Saúde - Manguinhos, Rio de Janeiro, v. 18, n. 3, p. 949-954, 2011. 
BENNETT, J. Thing-Power. In: BRAUN, B.; WHATMORE, S. J. Political matter: technoscience, democracy, and public life. Minnesota: Univerversity of Minnesota Press, 2010. p. 35-62.

BUHL, H.; ANDERSEN, M.; KEROSUO, H. I Work All Day with Automation in Construction: I am a Sociomaterial-Designer. In: Nordic Conference on Construction Economics and Organization, 10, 2019. Anais [...], 2019. Disponível em: https://www.researchgate.net/publication/334613019_I_Work_All_ Day_with_Automation_in_Construction_I_am_a_Sociomaterial-Designer. Acesso em: 2 jun. 2019.

DUIJN, M. Network society and public policy Networks. In: DUIJN, M. Embedded Reflection on public policy innovation: a relativist/pragmatist inquiry into the practice of innovation and knowledge. [S.I]: Eburon Academic Publishers, 2009. p. 79-84. Disponível em: http://ebookcentral. proquest.com/lib/bcufpb-ebooks/detail.action?doc. Acesso em: 10 fev. 2017.

FOX, N. J.; ALLDRED, P. Social structures, power and resistance in monist sociology: (new) materialist insights. Journal of Sociology, v. 54, n. 3, p. 315-330, 2018.

GEIGER, R. S.; RIBES, D. Trace ethnography: Following coordination through documentary practices. 2011. Disponível em: https://www.researchgate.net/publication/224221205_Trace_Ethnography_ Following_Coordination_through_Documentary_Practices. Acesso em: 19 jan. 2019.

GERRARD, J.; RUDOLPH, S.; SRIPRAKASH, A. The Politics of Post-Qualitative Inquiry: History and Power. Qualitative Inquiry, v. 23, n. 5, p. 384-394, 2017.

GREENE, J. C. On rhizomes, lines of flight, mangles, and other Assemblages. International Journal of Qualitative Studies in Education, v. 26, n. 6, p. 749-758, 2013.

HARMAN, G. Prince of networks: Bruno Latour and metaphysics. Melbourne: Re. Press, 2009.

KANGER, L. Mapping the ANT multiple: A comparative, critical and reflexive analysis. J. Theory Soc Behav., v. 47, p. 435-462, 2017.

LAET, M.; MOL, A. The Zimbabwe Bush Pump: Mechanics of a Fluid Technology Source. Social Studies of Science, v. 30, n. 2, p. 225-263, 2000.

LATOUR, B. Jamais fomos modernos: ensaio de antropologia simétrica. Rio de Janeiro: 34, 1994.

LATOUR, B. Por uma antropologia do centro. Revista Mana, Rio de Janeiro, Ano X, n. 2, p. 397414, out. 2004. 
LATOUR, B. Reagregando o social: uma introdução à teoria do Ator-rede. Salvador: Edufba, 2012.

LE GRANGE, L. What is (post)qualitative research? South African Journal of Higher Education, v. 32, n. 5, p. 1-14, 2018.

LEONARDI, P. M. Materiality, Sociomateriality, and Socio-Technical Systems: What Do These Terms Mean? How Are They Related? Do We Need Them? In: LEONARDI, P. M; NARDI, B. A.; KALLINIKOS, J. (ed.). Materiality and organizing: social interaction in a technological world. Oxford: Oxford University Press., 2012. p. 25-48.

LIMA, N. W.; OSTERMANN, F.; CAVALCANTI, C. J. H. A não-modernidade de Bruno Latour e suas implicações para a Educação em Ciências. Caderno Brasileiro de Ensino de Física, v. 35, n. 2, p. 367-388, 2018.

LONGO, M.; ZACKA, B. Political Theory in an Ethnographic Key. American Political Science Review, v. 113, n. 4, p. 1066-1070, 2019.

MAZZEI, L. A. A voice without organs: interviewing in posthumanist research. International Journal of Qualitative Studies in Education, v. 26, n. 6, p. 732-740, 2013.

MONTEIRO, M. S. A. Reconsiderando a Etnografia da Ciência e da Tecnologia: tecnociência na prática. Revista Brasileira de Ciências Sociais, v. 27, n. 72, p.139-151, 2012.

MÜLLER, M. Assemblages and Actor-Networks: rethinking socio-material power, politics and space. Geography Compass, v. 9, n. 1, p. 27-41, 2015.

ROSA, L. O.; FERREIRA, V. S.; SILVA, S. C. V. Elaboração e análise de redes de política. Revista de Estudios Teóricos y Epistemológicos en Política Educativa, v. 5, p. 1-12, 2020.

SCHUBERT, C. Akteur-Netzwerk Theorie. In: APELT, M. et al. (org.). Handbuch Organisationssoziologie. 2019. Disponível em: https://link.springer.com/referenceworkentry/10.10 07\%2F978-3-658-15953-5_16-1. Acesso em: 4 ago. 2019.

SEGATA, J. A Etnografia como promessa e o "Efeito Latour" no campo da cibercultura. Ilha, v. 16, n. 2, p. 69-87, 2014.

SØRENSEN, E. The materiality of learning: technology and knowledge in educational practice. Cambridge University Press, 2009.

ST. PIERRE, E. A. Writing Post Qualitative Inquiry. Qualitative Inquiry, v. 24, n. 9, p. 603-608, 2018 a. 
ST. PIERRE, E. A. Uma história breve e pessoal da pesquisa pós-qualitativa: em direção à "pósinvestigação". Práxis Educativa, Ponta Grossa, v. 13, n. 3, p. 1044-1064, set./dez. 2018b. Disponível em: https://www.revistas2.uepg.br/index.php/praxiseducativa. Acesso em: 5 jan. 2019.

TAYLOR, C. A. Is a posthumanist Bildung possible? Reclaiming the promise of Bildung for contemporary higher education, Higher Education, v. 74, n. 3, p. 419-435, 2017.

ULMER, J. B. Posthumanism as research methodology: inquiry in the Anthropocene. International Journal of Qualitative Studies in Education, 2017. Disponível em: http://www.ufrpe.br/sites/www. ufrpe.br/files/ulmer_2017._posthumanism_as_research.pdf. Acesso em: 4 out. 2019.

VIEIRA, B. M. A etnografia como metodologia de análise da política: dilemas e perspectivas do trabalho de campo. Revista Magistro, v. 2, n. 14, p. 88-106, 2016. 
2 Doutora em Educação - FACED/UFBA; Professora do Departamento de Ciência da Informação -UFPB; Membro do Grupo de Pesquisa Educação, Comunicação e Tecnologias - GEC/UFBA e do Laboratório de Tecnologias Intelectuais - LTi/UFPB. E-mail: silva.131313@gmail.com

3 Doutor em Comunicação - USP; Professor Titular (e ativista) da Faculdade de Educação - UFBA; Líder do Grupo de pesquisa Educação, Comunicação e Tecnologias - GEC. E-mail: nelson@pretto.pro.br

4 Doutorando em Educação - UFBA; Membro do Grupo de Pesquisa Educação, Comunicação e Tecnologias - GEC/ UFBA. E-mail: lima.danillom@gmail.com 